Revista de Estudios Histórico-Jurídicos

[Sección historia del derecho indiano]

XLI (Valparaíso, Chile, 2019)

[pp. 289 - 302]

\title{
De ROMA A LIMA: LA RESTITUCIÓN A UN ESTADO ANTERIOR EN EL DERECHO INDIANO
}

[From Roma to Lima: Restitution to a Previous State in the "Derecho Indiano"]

\author{
JaKob Fortunat STAGL \\ Universidad de Chile*
}

\section{RESUMEN}

La restitución a un estado anterior (in integrum restitutio) nace en Roma como institución del derecho procesal que permite a personas incapaces tutelar sus derechos con el restablecimiento del estado o la posición jurídica anterior. En el derecho canónico medieval esta institución se convierte en algo como un cáncer jurídico que amenaza con reemplazar el derecho, vale decir, las reglas uniformes aplicadas de manera regular, por la equidad, es decir, la arbitrariedad del juez competente. En el nuevo mundo esta institución cambia de rumbo y se convierte en la base teórica para la construcción del estado jurídico de los indios. Este estado se puede describir como persona tutelada (persona miserabilis) y es un término medio entre la alternativa más radical de la equiparación de los indios a los otros súbditos del Rey o la privación de sus derechos.

\section{Palabras Clave}

In integrum restitutio - persona miserabilis - derecho indiano - Las Casas - Solórzano.

\section{ABSTRACT}

The restitution to a previous state (in integrum restitutio) was born in Rome as an institution of procedural law that allows people unable to protect their rights with the restoration of the state or previous legal position. In medieval canon law this institution becomes something like a legal cancer that threatens to replace the law, that is, the uniform rules applied on a regular basis, for equity, that is, the arbitrariness of the competent judge. In the new world, this institution changes course and becomes the theoretical basis for the construction of the legal status of the Indians. This state can be described as a protected person (persona miserabilis) and is a middle term between the most radical alternative between the equalization of the Indians to the other subjects of the King or the deprivation of their rights.

\section{KEYWORDS}

-In integrum restitution - persona miserabilis - "Derecho Indiano" - Las Casas - Solórzano.

RECIBIDO el 24 de septiembre de 2018 y ACEPTADO el 3 de julio de 2019

*Prof Dr. iur., Profesor de Introducción al Derecho y Derecho Romano, Facultad de Derecho, Universidad de Chile. Dirección postal: Pío Nono Nº1, Providencia, Santiago de Chile. Dirección electrónica: jakob.stagl@yahoo.de. Este artículo es parte del proyecto Fondecyt Regular No 1170316 "The Systematization of Roman Law”, del cual el autor es investigador principal. 


\section{LA RESTITUTIO IN INTEGRUM COMO INSTITUCIÓN DEL DERECHO CANÓNICO}

La restitución a un estado anterior - restitutio in integrum - es una institución bien demarcada del derecho canónico. Según una definición muy común, restitutio in integrum se puede entender de la manera siguiente: est prioris status vel iuris redintegratio ${ }^{1}$ (es el restablecimiento del estado o de la posición jurídica anterior). Es importante tener presente que la restitutio in integrum no mira a la restitución de una cosa como la condictio, sino más bien hacia la revocación de un acto jurídico, dado que es una institución del derecho procesal ${ }^{2}$. Esta institución, que tiene sus raíces en el derecho romano ${ }^{3}$, fue aceptada y desarrollada por el derecho canónico y tiene su sedis materiae en el primer libro del Liber Extra (X 1,41,1$10)^{4}$. Originariamente se refería a la restitución o compensación de un daño o una desventaja sufrida por un menor, en casos de violencia o de ausencia (plazos). Pero ya en el Liber Extra (X 2,13,13-14) $)^{5}$ se extiende esta institución jurídica a los efectos del matrimonio, y el Liber Sextus $(1,21,1-2)^{6}$ y las Clementinae $(1,11,1)^{7}$ van en la misma dirección. Gracias a este desarrollo, se puede ver que en el alto medievo la restitutio in integrum había tomado un rumbo hacia la expansión ${ }^{8}$. Por consiguiente, ya la glosa a X 1,41, $1^{9}$ (rubrum) habla de una restitutio generalis per quam subvenitur ecclesiis et minoribus ${ }^{10}$ (una restitución general con la cual se ayuda a los menores y a la Iglesia).

Con eso, la restitutio in integrum se había desarrollado en el Corpus Iuris Canonici en un p r i n c i p i o, como escribe Helmholz ${ }^{11}$, que permite a cada persona lesionada de manera poco equitativa, por un negocio jurídico o un procedimiento jurídico, aunque por lo demás formalmente legal, anular tales efectos. El negocio forzado fue simplemente un ejemplo [del Corpus Iuris Canonici] para un principio moral general. "La consecuencia de este principio radica en que todo tipo de

\footnotetext{
${ }^{1}$ Pereyra, Benedicto, Elucidarium sacrae theologiae moralis et juris utriusque: exponens universum idioma, id est proprietatem sermonis theologici, canonici, \& civilis (Venetiis: sumptibus Combi \& Lanouii, 1678), p. 894.; también FeEneY, Tomas John, Restitutio in integrum (Washington D.C., 1941), p. 26.

${ }^{2}$ Helmholz, Richard H., Kanonisches Recht und europäische Rechtskultur (Tübingen, 2013), p. 95.

${ }^{3}$ Kaser, Max, Das Römische Privatrecht (2a ed., München, 1971), I, p. 277; KASER, Max; HACKL, Karl, Das römische Zivilprozessrecht (2a ed., München, 1996), p. 351. KuPISCH, Berthold, In integrum restitutio und vindicatio utilis bei Eigentumsübertragungen im klassischen römischen Recht (Berlin, 1974), pp. 1 ss.

${ }^{4}$ Odd, Sforza degli, De restitutione in integrum tractatus (ed., Colonia Agrippina, 1705) trata el tema profundamente.

${ }^{5}$ Gregorio IX, Liber Extra. Corpus Iuris Canonici (1234), 2,13. pp. 13-14.

${ }^{6}$ Bonifacio VIII, Liber Sextus. Corpus Iuris Canonici (1298), 1,21. pp. 1-2.

${ }^{7}$ Las Clementinae, Corpus Iuris Canonici (1314), 1,11, p. 1.

${ }^{8}$ Helmholz, Richard H., cit. (n. 3), p. 104. Un reflejo se puede encontrar en las Siete Partidas que dan amplio espacio a esta instiución, sobre todo en el Título 23 de la Tercera Partida y el Título 19 de la Sexta Partida.

${ }^{9}$ Gregorio IX, Liber Extra. Corpus Iuris Canonici (1234), X 1,41,1.

${ }^{10}$ Glosa al Corpus Iuris Canonici, citada por la edición Venecia (1605).

${ }^{11}$ Helmholz, Richard H., cit. (n. 2), p. 104.
} 
mandamiento jurídico puede ser impugnado con la restitutio in integrum"12. La expresión más evidente de esta tendencia hacia un instrumento jurídico universal para la realización de la equidad en detrimento de la seguridad jurídica es la obra de Sforza degli Oddi (1540-1611) De restitutione in integrum, que trata del tema en 700 páginas con todos los detalles imaginables e inimaginables.

Pero ¿cuál es el "principio moral general” detrás de la restitutio in integrum? El Liber Extra dice Ecclesia iure minoris debeat semper illaesa servari (la Iglesia debe siempre proteger la ilesidad de los menores) ${ }^{13}$. Se puede constatar entonces que la restitutio in integrum es una consecuencia de la aequitas canonica ${ }^{14}$ (Decretum Gratiani Dist. 45 c. 10) ${ }^{15}$ y ésta comprende en hacer primar la epieikeia, la justicia en casos particulares ${ }^{16}$, especialmente cuando están involucradas personas débiles, realizando de esta manera las virtudes de caritas y misericordia ${ }^{17}$.

Por lo general, se debe entender la restitutio in integrum como instrumento jurídico para realizar la justicia en casos particulares en contra de la seguridad jurídica y los principios generales, y los que suelen beneficiarse de ese principio son los débiles, como los menores ${ }^{18}$.

\section{LA INTEGRUM RESTITUTIO EN EL DERECHO CANÓNICO DE HISPANOAMÉRICA}

\section{Introducción}

La restitutio in integrum llegó a Hispanoamérica en forma de una institución del derecho canónico normal, pero con una tendencia hacia una destrucción de la juridicidad del tal derecho (en cuanto el derecho está basado en la igualdad y seguridad, y si trata cada caso de manera particular, no hay más reglas) que, si bien tal potencial destructivo no se manifestó en el derecho canónico, sí lo hizo en el derecho real o temporal.

Como veremos a continuación, esta institución adquirió una nueva función en el Nuevo Mundo, que parece a primera vista una evolución natural de su potencial caótico y destructivo. No resulta completamente descabellado pensar que la in integrum restitutio, en cuanto concretización de la aequitas canonica, acabó siendo una institución tan importante gracias al hecho de que Suárez fue uno de los principales teóricos de la aequitas canonica en la doctrina clásica del derecho canónico ${ }^{19}$. Esta teoría clásica del derecho canónico se manifestó sobre

${ }^{12}$ Ibíd.

${ }^{13}$ Gregorio IX, cit. (n. 9), X 1,41,1.

${ }^{14}$ De manera exhaustiva sobre este tema, véase WohlHaupter, Eugen, Aequitas canonica. Eine Studie aus dem Kanonischen Recht (Paderborn, Schöningh, 1931), pp. 1 ss.; véase también Landau, Peter, "Aequitas" in the "Corpus Iuris Canonici", en Syracuse Journal of International Law and Commerce, 20 (1994), pp. 95-104.

${ }^{15}$ Feeney, Tomas John, cit. (n. 1), p. 1.

${ }^{16}$ Van Hove, Alphonse, De legibus ecclesiasticis (Mechliniae, Dessain, 1930), p. 281.

${ }^{17}$ Elsener, F, Gesetz, Billigkeit und Gnade im Kanonischen Recht, en Summum Ius Summa Iniuria: Individualgerechtigkeit Und Der Schutz Allgemeiner Werte Im Rechtsleben, (Tübingen, Mohr, 1963), pp. 177-190.

${ }^{18}$ Helmholz, Richard H., cit. (n. 2), p. 126.

${ }^{19}$ SuÁreZ, Francisco, Tractatus de legibus ac Deo legislatore: in decem libros distributus (Paris, 
todo en el manual de Murillo Velarde. El potencial de la restitutio in integrum de crear algo nuevo derrumbando lo viejo en el marco del derecho real o temporal, se manifiesta en otro autor del cual poseemos una exposición bastante completa de esta institución: Solórzano.

\section{La doctrina clásica: Murillo Velarde}

Partiendo de la definición clásica, Murillo Velarde aclara que la restitutio in integrum puede conferir una acción, pero puede funcionar también como excepción contra la acción de otro que mira al restablecimiento de la condición inicial del beneficiario ${ }^{20}$. En armonía con la doctrina clásica, se dice que el perjuicio del beneficiario que se define debe ser considerable (laesio enormis) ${ }^{21}$-refiriéndose a negocios jurídicos privados- con el criterio del Codex Iustiniani ${ }^{22}$ de la reducción a la mitad del verdadero valor ${ }^{23}$.

La restitutio in integrum se dirige contra negocios jurídicos privados, como la aceptación de una herencia ${ }^{24}$, o contra contratos que pueden ser anulados basándose en ella ${ }^{25}$. También todo tipo de acto jurídico hacia la justicia puede ser anulado como una apelación dañina o una declaración como testigo si el procedimiento no era regular, también puede anularse una adopción ${ }^{26}$. Basándose en la restitutio in integrum se puede subsanar la dilación de un probatorio ${ }^{27}$.

Beneficiarios de la in integrum restitutio son: los menores de edad, los ausen$\operatorname{tes}^{28}$, la Iglesia, es a decir una parroquia, un monasterio u orden eclesiástica, etc., clérigos, en cuanto actúan en nombre de la Iglesia, el gobierno y finalmente el monarca, actuando en nombre de la Corona ${ }^{29}$. Si uno de los dos socios de una sociedad, por ejemplo, es un beneficiario, ambos pueden pedir la integrum restitutio si no es posible dividir sus efectos ${ }^{30}$.

El iudex competens no está estrictamente vinculado por el alcance de la peti-

1613), lib. 1, cap. 2 n. 9 y lib. 2 cap. 16; sobre esto, véase WohlHaupter, Eugen, cit. (n. 14), pp. 94-96 y VAN Hove, Alphonse, cit. (n. 16), p. 276.

${ }^{20}$ Murillo Velarde, Pedro, Cursus juris canonici hispani et indici: in quo juxta ordinem titulorum Decretalium non solum canonicae decisiones [...], (3a ed., Matriti, Typographia Ulloae a Ramone Ruiz, 1791), Libro II, Tít. XXII. De la fe de los instrumentos, no 394.

${ }^{21}$ Ibíd., no 395.

${ }^{22}$ Diocl. / Maxim. Cod. Just. 4.44.2: Rem maioris pretii si tu vel pater tuus minoris pretii, distraxit, humanum est, ut vel pretium te restituente emptoribus fundum venditum recipias auctoritate intercedente iudicis, vel, si emptor elegerit, quod deest iusto pretio recipies. Minus autem pretium esse videtur, si nec dimidia pars veri pretii soluta sit. (a. 285).

${ }^{23}$ Murillo Velarde, Pedro, cit. (n. 20), Libro II, Tít. XXII. De la fe de los instrumentos, no 396.

${ }^{24}$ Ibíd., no 394, 396.

${ }^{25}$ Ibíd., no 396.

${ }^{26}$ Ibíd.

${ }^{27}$ Hevia Bolaños, Juan de, Curia Philipica: primero y segundo tomo (Madrid, Ramón Ruiz, Imprenta de Ulloa, 1790), I, Parte I, párrafo 16, fol. 21.

${ }^{28}$ Ibíd., I, Parte I, párrafo 18, fol. 9.

${ }^{29}$ Murillo Velarde, Pedro, cit. (n. 20), Libro II, Tít. XXII. De la fe de los instrumentos, no 397.

${ }^{30}$ Ibíd., no 397. 
ción y puede tomar la decisión adecuada dentro el marco del officium indicis ${ }^{31}$. La petición de la restitutio in integrum presupone una iusta causa, por ejemplo, la persona lesionada estaba fuera del país o ésta actuó bajo presión, o estaba enferma, o presa, o se trata de una persona que normalmente no conoce muy bien el derecho, como menores, soldados, rústicos o mujeres ${ }^{32}$.

No se puede solicitar una restitutio in integrum en el campo del derecho espiritual, respecto a sacramentos como el matrimonio, pero eso no se refiere a negocios relacionados con este sacramento como la constitución de una dote ${ }^{33}$. El menor no se puede beneficiar de la restitutio in integrum si él mismo es culpable de dolo malo ${ }^{34}$; tampoco pueden beneficiarse los que habían sido declarados mayores de edad anteriormente ${ }^{35}$; a su vez no puede si confirman como mayores lo que habían hecho anteriormente como menores ${ }^{36}$; tampoco pueden, si simulan ser mayores ${ }^{37}$; ni en el caso de una renuncia eficaz ${ }^{38}$; tampoco si el daño sufrido no ha sido causado por la edad sino que es una mera casualidad ${ }^{39}$; tampoco contra una sentencia a favor de la libertad del menor, contra una prestación a favor del menor ordenada por la justicia. El menor con conocimientos jurídicos, como jóvenes juristas, por ejemplo, no pueden pedir la in integrum restitutio ${ }^{40}$, ni el privilegiado contra el privilegiado ${ }^{41}$.

Respecto al procedimiento, permanecen vigentes los principios normales: el menor debe probar el daño que ha sufrido por negocio jurídico o acto jurídico estatal, y su edad. Es posible ser asesorado por un abogado o tutor ${ }^{42}$.

Se debe solicitar la restitutio in integrum dentro de un plazo de 4 años, que empieza a correr con el vigésimo quinto cumpleaños, aunque en otros casos comienza a correr con el daño o cuando se regresa a la patria ${ }^{43}$. Dentro de un proceso pueden estar en vigencia otras reglas: el privilegiado tiene quince días para recuperar un probatorio ${ }^{44}$.

Como puede observarse, esta doctrina de la in integrum restitutio es una exposición normal y clásica del derecho canónico sin adaptarse a las nuevas condiciones y circunstancias del Nuevo Mundo, no aludiéndose por tanto al contexto americano o colonial de una manera específica. De este modo, el potencial destructivo no

\footnotetext{
${ }^{31}$ Ibíd., no 398.

${ }^{32}$ Ibíd.

${ }^{33}$ Ibíd., no 399.

${ }^{34}$ Ibíd.

${ }^{35}$ Ibíd.

${ }^{36}$ Ibíd.

${ }^{37}$ Ibíd.

${ }^{38}$ Ibíd.

${ }^{39}$ Ibíd.

${ }^{40}$ Hevia Bolaños, Juan de, cit. (n. 27), I, Parte I, párrafo 16, fol. 23.

${ }^{41}$ Murillo Velarde, Pedro, cit. (n. 20), Libro II, Tít. XXII. De la fe de los instrumentos, no 399 y también Hevia Bolaños, Juan de, cit. (n. 27), I, Parte I, párrafo 16, fol. 23.

${ }^{42}$ Murillo Velarde, Pedro, cit. (n. 20), Libro II, Tít. XXII. De la fe de los instrumentos,

${ }^{43}$ Ibíd., no 402.

${ }^{44}$ Hevia Bolaños, Juan de, cit. (n. 27), I, Parte I, párrafo 16, fol. 25.
} no 400 . 
toma forma en el derecho canónico, pero sí, como tendremos la oportunidad de ver a continuación, en el derecho real o temporal.

\section{La doctrina de Solórzano: los indios como personae miserabilis}

a) los indios como personae miserabiles en el derecho temporal

Solórzano, el padre del derecho indiano, tenía un acercamiento mucho más político. En su obra sobre la Política indiana expone que los indios, como grupo étnico, deben calificarse como personae miserabiles ${ }^{45}$ citando varias otras autoridades ${ }^{46}$. Lo mismo había declarado con más autoridad el tercer concilio de Lima, que simultáneamente insiste, en armonía con el papa y el rey, en que los indios no pueden ser esclavizados ${ }^{47}$.

El concepto de persona miserabilis también proviene del derecho romano ${ }^{48}$. Su significado original es que los pobres, viudas y huérfanos tienen su foro en el lugar donde viven, para excusarlos de los gastos enormes de un proceso en otro $\operatorname{lugar}^{49}$. El derecho canónico había escogido este concepto de la misma manera que la restitutio in integrum y con intenciones similares, lo mismo vale para el derecho español proveniente de las Siete Partidas ${ }^{50}$. Los beneficiarios de esta institución casi no se pueden definir por su variedad, que depende mucho de las circunstancias del caso concreto ${ }^{51}$, la definición de la doctrina clásica es: homo miseratione dignus ${ }^{52}$. La consecuencia más importante de la calificación como persona miserable en el

${ }^{45}$ Fundamental sobre ese tema la obra de Álvarez de Velasco, Gabriel, De privilegiis pauperum et miserabilium personarum ad legem univam Codicis [...], (Lausonii \& Coloniae Allobrogum, 1739).

${ }^{46}$ Solórzano Pereira, Juan de, Politica indiana (Madrid, Imprenta Real de la Gazeta, 1776), lib. II, cap. 28, párrafo 3: "[...] aun quando no concurrieran en los Indios estas causas, para deber ser considerados entre las personas miserables, les bastàra recien convertidos à la Fè, à los quales se concede este titulo, $i$ todos los favores i privilegios que andan con él [...] hablando de los Indios, nuestro Gregorio Lopez, Matienzo, Alfaro i el Arçobizpo de Mexico don Fernando de Vega, que expressamente lo afirman, assi por esta razon, como por los demas, que dexo apuntadas, de su imbecilidad, rusticidad, pobreza, pussilanimidad, i continuos trabajos, i servicios". Sobre humanismo de Solórzano véase Levene, Ricardo, En el tercer centenario de "Política indiana" de Juan de Solórzano Pereira, 20 (Buenos Aires, Argentina, 1948), pp. 21 ss.; Malagón Barceló, Javier; Ots Capdequí, José María, Solórzano y la política indiana (2a ed., Ciudad de México, 1983), pp. 53 ss. La misma calificación de los indios como "personae miserabiles" se encuentra en José DE Acosta, Francisco Mateos, De procuranda Indorum salute. Proemium y I. c. 2 (SSLA); véase también De Matienzo, Juan, Gobierno del Perú (Editorial Buenos Aires, 1910), parte 1, cap. 4.

${ }^{47} \mathrm{Al}$ mismo tiempo cita al Concilio Limense III, acto 3, cap. 3, que declara que los indios no pueden ser esclavizados y deben ser tratados bien, p. 164.

${ }^{48}$ NovOA, Mauricio, Derecho romano y el indio americano en Solórzano, en BIRA., 26 (Lima, 1999), pp. 253-272.

${ }^{49}$ Cod. Just. 3,14,1.pr.-1. (a. 334).

${ }^{50}$ Por ejemplo, Escalante, Antonio de, Discurso breve a la majestad católica del rey nuestro señor don Felipe Cuarto el grande rey de las Españas (Madrid, 1638); sobre él y otros, vease NovOA, Mauricio, La práctica judicial y su influencia en Solórzano: la Audiencia de Lima y los privilegios de indios a inicios del siglo XVII, en BONNETT, Diana (coord.), Pensar la colonia desde la colonia (Bogotá, Ediciones Uniandes, 2006), pp. 143 ss.

${ }^{51}$ Helmholz, Richard H., cit. (n. 2), p. 143.

52 Álvarez de Velasco, Gabriel, cit. (n. 45), II, quaest. 2, párrafo 4. 
derecho canónico es la competencia de la justicia eclesiástica ex defectu iustitiae en lo que se llama el forum mixtum ${ }^{53}$.

El forum mixtum describe una situación en la cual la parte lesionada puede elegir si desea elevar sus quejas ante el fuero eclesiástico o ante el fuero estatal, en casos de conflicto será competente el fuero que ha sido invocado en primer lugar ${ }^{54}$. Esta competencia compartida con el fuero eclesiástico fue una de las ideas principales de Las Casas, y la Corona concedió la competencia eclesiástica solo reticentemente ${ }^{55}$.

El tertium comparationis en la persona miserable del derecho canónico y de los indios es su mala comprensión de las instituciones españolas, su falta de herramientas intelectuales y pecuniarias para defenderse contra los españoles, codiciosos y mejor dotados para usar el derecho como arma $^{56}$.

Después de haber descrito la situación de $\mathrm{m}$ i s e $\mathrm{r}$ a b l e s de los indios en términos muy claros, Solórzano escribe: "De los mismos principios se saca [...] que los indios [...] gocen de todos los favores, y privilegios, que, a los menores, pobres, rústicos, y otros tales se conceden" ${ }^{57}$. De estos forman parte señaladamente y en armonía con el derecho canónico clásico ${ }^{58}$ la restitutio in integrum ${ }^{59}$, lo que fue ya formulado en la ley 20 de 1542 por Carlos ${ }^{60}$.

La calificación de los indios como personas miserables en el sentido del derecho canónico y la aplicabilidad aliviada de la restitutio in integrum tiene, en el derecho temporal, las consecuencias siguientes, según Solórzano: i) no se presume en los indios dolo, ni engaño; ii) están libres de tutelas y otras cargas; iii) sus pleitos se han de determinar breve, y sumariamente, y sin atender escrupulosas fórmulas de derecho; iv) pueden venir, decir y alegar contra los instrumentos que hubieren prestado y contra las confesiones que sus abogados hubieren hecho y revocarlas, no solo in continente, sino cada vez y cuando les convenga y pedir nueva prueba y presentar nuevos testigos; v) no se practica en ellos la contumacia judicial; vi) tienen caso de Corte como las viudas, y pupilos; vii) están libres de las penas que incurren otros cuando no hacen Inventaría; viii) no hace falta para ellos dar una fianza antes de acusar a un corregidor ${ }^{61}$; ix) pueden anular los contratos, sobre

${ }^{53}$ Helmholz, Richard H., cit. (n. 2), pp. 96 ss; Duve, Thomas, Sonderrecht in der Frühen Neuzeit. Studien zum "ius singulare" und den "privilegia miserabilium personarum, senum" und "indorum" in Alter und Neuer Welt (Frankfurt am Main, Vittorio Klostermann, 2008), pp. 52 ss.

${ }^{54}$ Helmholz, Richard H., cit. (n. 2), pág. 129.

${ }^{55}$ Duve, Thomas, cit. (n. 53), pp. 77 ss.

${ }^{56}$ Sobre este aspecto, véase NovoA, Mauricio, La práctica judicial, cit. (n. 50), pp. 139 ss.

${ }^{57}$ Solórzano Pereira, Juan de, cit. (n. 46), lib. II, cap. 28, párrafo 24, p. 233.

${ }^{58}$ Novarius, Joannes Maria, De privilegiis miserabilium personarum tractatus (Lausonii et Colonia Allobrogum, 1739), Praeludium IV.

${ }^{59}$ Solórzano Pereira, Juan de, cit. (n. 46), lib. II, cap. 28, párrafo 25, p. 233.

${ }^{60}$ Recopilación de Leyes de los Reynos de las Indias, lib. II, título XV, Ley 83; y lib. V, título X, Leyes 10, 12, 13.

${ }^{61}$ Solórzano Pereira, Juan de, cit. (n. 46), lib. II, cap. 28, párrafo 39, p. 235. 
todos sí disponen sobre cosas de valor, como tierras ${ }^{62}$; $\mathrm{x}$ ) es muy importante para Solórzano que los indios no juren para no poner en peligro su alma ${ }^{63}$.

Los límites de los privilegios para los indios son los derechos de terceros que no deben ser contagiados por los privilegios de los indios ${ }^{64}$.

Solórzano tiene completamente claro que eso acabará en una discapacitación de los indios, una consecuencia que asume por el bien de los indios, como dice ${ }^{65}$. Insiste no obstante en que el rey no puede suprimir la capacidad jurídica de los indios por completo, siendo $\mathrm{li}$ b r e s $\mathrm{v}$ a s a $11 \mathrm{os}$ del rey ${ }^{66}$. Los indios pueden conservar su independencia, por ejemplo, respecto a los testamentos que pueden realizar en principio como deseen, pero solo de manera abierta y pública ante un funcionario público ${ }^{67}$. Tan libres entonces no son.

La consecuencia lógica de esta discapacitación parcial es obviamente que los indios necesitan una especie de t u t o r , como dice Solórzano ${ }^{68}$, y éste es el protector de indios ${ }^{69}$.

b) Los privilegios de los indios en el derecho espiritual

Al contrario de lo que dice Murillo Velarde, la calificación como persona miserabilis tiene, según Solórzano, ciertas consecuencias limitadas en el ámbito e s p i r i t u a l: i) los matrimonios no se separan automáticamente si uno de los cónyuges no está bautizado (Concilio de Lima II y III), hay un periodo de transición de seis meses $^{70}$; ii) si un indio está casado con varias mujeres y quiere hacerse bautizar, debe elegir la primera o la que quiere más, si no se recuerda más quién fue la primera ${ }^{71}$; iii) pero no hay dispensación de edad legal para el matrimonio ${ }^{72}$; iv) los matrimonios incestuosos, sin embargo, deben ser separados antes del bautismo ${ }^{73}$; v) las indulgencias se pueden obtener solo por confesión y penitencia ${ }^{74}$; vi) los indios reciben el sacramento de la comunión aun si no entienden perfectamente su sentido religioso ${ }^{75}$, especialmente el Sacramento de la unción de los enfermos (viático) ${ }^{76}$; vii) los indios no deben guardar las fiestas con tanta rigidez como los otros, pero sus dueños no pueden forzarlos a trabajar en días de fiestas, como habían opinado algunos autores ${ }^{77}$; viii) los indios son

\footnotetext{
${ }^{62}$ Ibíd., párrafo 42, p. 236.

${ }^{63}$ Ibíd., párrafo 33, p. 234.

${ }^{64}$ Ibíd., párrafo 31, p. 234.

${ }^{65}$ Ibíd., párrafo 44, p. 236.

${ }^{66}$ Ibíd., párrafo 45, p. 236.

${ }^{67}$ Ibíd., párrafo 55, p. 238.

${ }^{68}$ Ibíd., párrafo 51, p. 238.

${ }^{69}$ Ibíd., párrafo 46 ss, p. 237.

${ }^{70}$ Ibíd., lib. II, cap. 29, párrafo 3, p. 239.

${ }^{71}$ Ibíd., párrafo 3, p. 239.

${ }^{72}$ Ibíd., párrafo 3, p. 239.

${ }^{73}$ Ibíd., párrafo 5, p. 240.

${ }^{74}$ Ibíd., párrafo 6, p. 240.

${ }^{75}$ Ibíd., párrafo 7, p. 240.

${ }^{76}$ Ibíd., párrafos 8-10, p. 240.

${ }^{77}$ Ibíd., párrafo 18, pág. 241.
} 
admitidos al sacerdocio ${ }^{78}$, pero hubo un debate sobre esta cuestión; ix) también pueden probar su nobleza para tener acceso a puestos oficiales.

c) la evolución de un ius singulare

La operación jurídica fundamentalmente de Solórzano consiste en una combinación de los dos conceptos de personae miserabiles y restitutio in integrum. Calificando a los indios como personas miserables, los juristas abren las puertas de la justicia eclesiástica para ellos y los sitúan, consecuentemente, bajo la protección de la Iglesia. Y dentro de la justicia eclesiástica pueden acogerse a la restitutio in integrum $^{79}$. La combinación por parte de Solórzano y otros ${ }^{80}$ de las dos instituciones, una que abre las puertas de la justicia eclesiástica y la otra que dé el poder de deshacer todo tipo inequidad, es la base de la creación de un ius singulare ${ }^{81}$, un derecho particular para los indios que, atendiendo a su lógica intrínseca, se manifiesta en cuanto tal no fundamentalmente en el derecho canónico, sino más bien en el derecho real o temporal. La creación de tal derecho es necesaria para proteger a los indios del derecho común español, que sería un arma legal contra ellos en manos de los españoles. La consecuencia reside en que la institución del protector de indios y del fuero mixto se secularizan a favor de la Corona.

\section{d) consecuencias teóricas y prácticas}

Protector de indios: es obvio que la consecuencia inmediata de esta construcción jurídica es, como ya habíamos dicho, la necesidad de un tutor para los indios, y éste es el protector de indios ${ }^{82}$. El primero que ostentó este cargo fue Bartolomé de las Casas, instaurado por Carlos $\mathrm{I}^{83}$. Las Casas dice: "Porque la experiencia, maestra de todas las cosas, enseña ser necesario en estos tiempos renovar todos los cánones en que se manda que los obispos tengan cuidado de los pobres cautivos, hombres afligidos y viudas, y que incluso derramen su sangre por ellos, según son obligados por ley natural y divina" ${ }^{\prime 4}$. Este cargo tiene ya una historia larga en el derecho español

${ }^{78}$ Esta cuestión estaba discutida; véase Solórzano Pereira, Juan de, cit. (n. 46), lib. II, cap. 29, párrafos 23-31, pp. 242-243.

${ }^{79}$ Ibíd., lib. II, cap. 28, párrafo 25, p. 242.

${ }^{80}$ Ibíd., párrafo 24, p. 242: "que los Indios, por las razones referidas, son miserables personas, tampoco la tiene, que ayan de gozar, i gozen de todos los favores i privilegios que a los menores, pobres, rusticos $i$ otros tales se conceden, assi en los judicios, como en semejantes casos lo dixeron Baluds, $i$ otros autores./por el consiguiente, les compete el beneficio de la restitucion in integrum: no se presume en ellos dolo ni engaño [...]". Álvarez De Velasco, Gabriel, cit. (n. 45), quaest. 25, n. 19, p. 1.

${ }^{81}$ Sobre las raíces del ius singulare en el derecho romano: STAGL, Jakob, Favor dotis - Die Privilegierung der Mitgift im System des römischen Rechts (Böhlau, Viena, Austria, 2009), pp. 317 ss., y STAGL, Jakob, Das "testamentum militare" in seiner Eigenschaft als "ius singulare", en Revista de Estudios Histórico-Jurídicos, 36 (2014), pp. 129, 142 ss., y sobre el derecho canónico, especialmente en Hispano-América, véase Duve, Thomas, cit. (n. 53), pp. 145 ss., 269 ss.

${ }^{82}$ NovoA, Mauricio, The Protectors of Indians in the Royal Audience of Lima: History, Careers and Legal Culture, 1575-1775 (Leiden-Boston, 2016), p. 11; y Ruigómez Gómez, Carmen, Una politica indigenista de los Habsburgo: el protector de indios en el Perú (Madrid, 1988), pp. 35 ss., 45 ss.

${ }^{83}$ Novoa, Mauricio, La práctica judicial, cit. (n. 50), p. 17.

${ }^{84}$ De las Casas, Bartolomé, Petición a su Santidad Pio V(1566), en Cartas y memoriales, en Obras completas (Madrid, 1995), XIII, p. 370. 
antiguo $^{85}$. El cargo del protector de indios, que antes estaba en las manos de la Iglesia, le fue retirado a ésta a finales de siglo XVI y puesto en las manos de un funcionario estatal ${ }^{86}$.

Juzgado general de indios: otra consecuencia obvia de la calificación como personas miserables de los indios es el establecimiento de una jurisdicción especial para sus asuntos, un juzgado general de indios. En base a una real cédula, se estableció en la audiencia de México el juzgado general de los indios. Era competente en juicios de los indios entre ellos y de españoles contra indios, siendo los pleitos de los indios contra españoles, por el contrario, competencia de tribunales ordinarios ${ }^{87}$. También tenía competencia en el derecho penal. La gran mayoría de los casos eran disputas de propiedad por tierras. Debemos un análisis minucioso de una cantidad significativa de fallos de la Corte de Indios entre agosto y septiembre de 1784 a Borah $^{88}$. Resulta que los indios usaban mucho esta posibilidad. La misma observación fue realizada por Owensby que también observa que los juicios no eran algo nuevo en la cultura de los aztecas ${ }^{89}$.

La "restitutio in integrum" en la práctica: la restitutio in integrum, como la construye Solórzano no es pálida teoría, por el contrario, conocemos algunos casos espectaculares, gracias a la investigación de Novoa: la nieta del último inca, Ana María de Loyola Coya, marquesa de Santiago de Oropesa (1594-1630) pidió 340.000 pesos de la Corona ante la real audiencia de Lima basándose en la le s i ó n e n o r m ís i m a que había sufrido por la Corona ${ }^{90}$. Hay casos de indios amparándose en la restitutio in integrum como remedio de la contumacia procesal en un litigio por el c a c i c a z g o, un caso en cual fue involucrado el mismo Solórzano como oidor ${ }^{91}$. La corte funda su decisión de conceder la presentación de testigos para probar el linaje después de la sentencia ya pronunciada (sic) con en el racionamiento siguiente: "No avia podido ni avia hecho provanza alguna por lo cual avia quedado yndefenso y le competia el beneficio de la restitucyon yn yntegrum contra el lapso del tiempo y omissa provanza por ser come hera yndio fraxil y persona miserable" ${ }^{\prime 2}$. Lo mismo ocurrió en otro caso acontecido entre 1621 y 1625 en Lima ${ }^{93}$, en este caso el procurador general de indios, Francisco de Arriola, presentó un escrito en el proceso en el cual dijo que el demandante es

${ }^{85}$ NovoA, Mauricio, La práctica judicial, cit. (n. 50), pp. 11 ss.; Ruigómez Gómez, Carmen, cit. (n. 82), pp. 37 ss.

${ }^{86}$ Ruigómez Gómez, Carmen, cit. (n. 82), pp. 67 ss.

${ }^{87}$ Arranz Lara, Nuria, Instituciones de derecho indiano en la Nueva España (Editora Norte Sur, 2000), p. 87.

${ }^{88}$ BoraH, Woodrow, Justice by Insurance: The General Indian Court of Colonial Mexico and the Legal Aides of the Half-Real (Berkeley: University of California Press, 1983), pp. 128 ss.

${ }^{89}$ Owensby, Brian P., Empire of Law and Indian Justice in Colonial Mexico (Stanford, 2008), pp. 40 ss.

${ }^{90}$ NovoA, Mauricio, La práctica judicial, cit. (n. 50), pp. 130 ss.

${ }^{91}$ Ibíd., pp. 132 ss.

${ }^{92}$ Causa de don Gerónimo Polan, indio, con Francisco Chancoy sobre el cacicazgo del pueblo de Begueta del distrito del villa de Chancay, 1621-1625, citado por NovoA, Mauricio, Ibíd., p. 227 n. 66.

${ }^{93}$ Ibíd., pp. 134 ss. 
una "persona miserable" y tenía entonces derecho a la restitutio in integrum "contra el paso del tiempo y omissa probanza" ${ }^{4}$.

También la regla alegada por Murillo Velarde, que la in integrum restitutio solamente se puede aplicar en la relación de una parte d é b i 1 y una parte f u e r t e con la consecuencia de estar excluida en el caso de una acción de un indio contra un indio, tiene resonancia en la práctica como demuestra la sentencia del procurador de indios de Perú, José Mejía de Estela, de $1705^{95}$.

Se pregunta cómo fue posible celebrar contratos válidos con indios, si ellos tenían siempre la posibilidad de ampararse en su condición de persona miserable, solicitando la restitutio in integrum. La solución estaba, como lo demuestra el caso de proceso entre Juana Sánchez, una india, y Antonio de Bobadilla, un español, por una casa en Lima en el año 1593, en una aprobación anterior por parte del protector general de indios, como explica el abogado de la India en su alegato final ${ }^{96}$. Como lo demuestra el registro del notario limense Francisco Cayetano de Arredondo, de 1723, la gran mayoría de los contratos entre indios con españoles se celebró con aprobación del procurador de indios -tal como lo había sugerido Solórzano ${ }^{97}-$.

Para garantizar la certeza del derecho fue también posible que ambas partes renunciaran al beneficio de pedir la restitutio in integrum bajo la supervisión del protector de indios, como en un caso de Huamanga (Perú) del año 1739, en el cual las partes hacen exactamente eso ${ }^{98}$.

\section{La ideología detrás de la construcción}

La construcción de Solórzano, y otros como De la Peña Montenegro"99, transforma dos instituciones del derecho canónico: la restitutio in integrum y la persona miserable: La restitutio in integrum pierde definitivamente su carácter de institución de justicia individual y la persona miserabilis adquiere un sentido étnico que antes no tenía ${ }^{100}$, como la restitutio in integrum, que tampoco tenía un carácter étnico ${ }^{101}$. El carácter étnico y entonces, se podría decir, esencialmente colonial, lo demuestra el hecho de que tanto marquesas como gente humilde caen bajo la misma categoría de personae miserabilis ${ }^{102}$ que puede ampararse de la restitutio in integrum. El resultado de la conexión de las dos instituciones es un derecho particular para los indios ${ }^{103}$, no visto como grupo social, sino como raza inferior. En este aspecto se puede interpretar la posición de Solórzano como

\footnotetext{
${ }^{94}$ Ibíd., p. 135.

${ }^{95}$ Ibíd., pp. 137 ss.

${ }^{96}$ Ibíd., pp. 136 ss.

${ }^{97}$ Solórzano Pereira, Juan de, cit. (n. 46), lib. II, cap. 28, pp. 42 ss.

${ }^{98}$ NovoA, Mauricio, The Protectors, cit. (n. 82), p. 228.

${ }^{99}$ De la Peña Montenegro, Alonso, Itinerario para párrocos de indios (Madrid, Ioseph Fernández de Buendía, 1668), I, pp. 387 ss.

${ }^{100}$ Novarius, Joannes Maria, cit. (n. 58), Sectio Prima, Praeludium VIII, p. 9.

${ }^{101}$ ODDI, Sforza degli, cit. (n. 4), quaest. 3-4.

${ }^{102}$ Véase también NovOA, Mauricio, La práctica judicial, cit. (n. 50), p. 147.

${ }^{103}$ Similar la opinión de NovOA, Mauricio, The Protectors, cit. (n. 82), p. 226.
} 
un tipo de racismo necesario para justificar el dominio de los españoles sobre Hispanoamérica.

Esta posición de Solórzano constituye el compromiso de dos posiciones extremas: es consabido tras algunas dudas iniciales, que el papa y el rey, y respectivamente el emperador, establecieron que los indios no pueden ser esclavizados, que deben ser tratados como vasallos del rey. Pero ¿cómo tratar a la gran masa de indios que tenían una civilización completamente diversa y muy variada entre ellos?, pues no se pueden comparar los mayas o los aztecas con los mapuches de Chile. ¿Cómo convivir con esta gente? Hubo dos respuestas completamente antagónicas. La más noble y romántico-idealista fue la respuesta de Vitoria. El gran iusnaturalista postulaba la autonomía cultural y política de los indios, sin olvidar el mandato de la Iglesia para la misión, por supuesto. La otra posición, cínica y fría, corresponde a una parte de los funcionares públicos de tratar a los indios como otros sujetos de la Corona española, con la consecuencia evidente de que el derecho se convirtiera en un arma contra los indios, que simplemente no eran capaces de defenderse por el motivo de que no tenían las mismas nociones de derecho romano que los españoles. Hubiera sido un juego del cual no se conocen ni las reglas ni el sentido. Su expropiación total y aniquilación social hubiera sido la consecuencia lógica. La posición de Solórzano se explica como compromiso. Los indios son libres, son vasallos de pleno derecho del Rey que pueden acceder a los cargos de oficial y de cura, pero deben ser tratados como menores, con la Iglesia actuando como su tutor, que les protege hacia fuera y les educa, les misiona por dentro ${ }^{104}$. Esta forma de integrar a los indios en el sistema jerárquico español como pupilos de la Iglesia, está conforme con las ideas jerárquicas y autoritarias o patronizantes de Solórzano ${ }^{105}$. Para proteger a los indios, se les sujeta a una especie de esclavitud ligera bajo el control de Iglesia, vigilando su interés y la salvación de su alma.

Esta interpretación explicaría también por qué Murillo Velarde, quien bien escribe 100 años después de Solórzano, no habló de los indios. Su libro es un libro de derecho canónico en las Indias, pero no para indios. La represión del problema de los indios en el derecho canónico es la consecuencia de la represión del forum mixtum y la monopolización del derecho en la justicia estatal. La evolución del cargo de Protector de Indios de Las Casas hacia un funcionario público ordinario es un fenómeno paralelo.

\section{Perspectivas para la investigación}

No existe hasta ahora literatura que trate directamente de la restitutio in integrum en el derecho canónico en Hispanoamérica. El análisis hasta ahora más exhaustivo se encuentra en las obras de Novoa citadas en las notas, estas obras permiten sobre todo ver la armonía existente entre teoría y práctica a propósito de la restitutio.

${ }^{104}$ Borah, Woodrow, cit. (n. 88), pp. 39 ss.

${ }^{105}$ De Ayala, Francisco Javier, Ideas politicas de Juan de Solórzano (Sevilla, 1946), pp. 428 ss. 


\section{BiBLIOGRAFÍA}

Corpus doctrinal

Concilium Limense celebratum anno 1583 sub Gregorio XIII [...]: iussu catholici regis Hispaniarum atq[ue] Indiarum, Philippi Secundi (Madriti, ex officina Petri Madrigalis Typographi, 1591).

De la Peña Montenegro, Alonso, Itinerario para párrocos de indios (Madrid, Ioseph Fernández de Buendía, 1668).

Hevia Bolaños, Juan de, Curia Philipica: primero y segundo tomo (Madrid, Ramón Ruiz, Imprenta de Ulloa, 1790).

Las Siete partidas del Sabio Rey don Alonso el Nono / nuevamente glosadas por el licenciado Gregorio López (Salamanca, Andrea de Portonaris, 1555).

Murillo Velarde, Pedro, Cursus juris canonici hispani et indici: in quo juxta ordinem titulorum Decretalium non solum canonicae decisiones [...], (3a ed., Matriti, Typographia Ulloae a Ramone Ruiz, 1791).

Recopilación de Leyes de los Reynos de las Indias, mandadas imprimir y publicar por la Magestad católica del rey don Carlos II (Madrid, Iván de Paredes, 1681), 4 tomos.

Solórzano Pereira, Juan de, Politica indiana (Madrid, Imprenta Real de la Gazeta, 1776), 2 tomos.

Fuentes secundarias

Álvarez de Velasco, Gabriel, De privilegiis pauperum et miserabilium personarum ad legem univam Codicis [...], (Lausonii \& Coloniae Allobrogum, 1739).

Arranz Lara, Nuria, Instituciones de derecho indiano en la Nueva España (Editora Norte Sur, 2000).

Bonifacio VIII, Liber Sextus. Corpus Iuris Canonici (1298).

BoraH, Woodrow (1983), Justice by Insurance: The General Indian Court of Colonial Mexico and the Legal Aides of the Half-Real (Berkeley: University of California Press, 1983).

Código de Justiniano (534).

De Ayala, Francisco Javier, Ideas políticas de Juan de Solórzano (Sevilla, 1946).

De las Casas, Bartolomé, Petición a su Santidad Pio V (1566), en Cartas y memoriales, en Obras Completas (Madrid, 1995), XIII.

De Matienzo, Juan, Gobierno del Perú (Editorial Buenos Aires, 1910).

Duve, Thomas, Sonderrecht in der Frühen Neuzeit. Studien zum "ius singulare" und den "privilegia miserabilium personarum, senum" und "indorum" in Alter und Neuer Welt (Frankfurt am Main, Vittorio Klostermann, 2008).

ElSener, F, Gesetz, Billigkeit und Gnade im Kanonischen Recht, en Summum Ius Summa Iniuria: Individualgerechtigkeit Und Der Schutz Allgemeiner Werte Im Rechtsleben (Tübingen, Mohr, 1963), pp. 168-190.

Escalante, Antonio de, Discurso breve a la Majestad católica del Rey Nuestro Señor Don Felipe Cuarto el grande Rey de las Españas (Madrid, 1638).

FeEney, Tomas John, Restitutio in integrum (Washington D.C., 1941).

Gregorio IX, Liber Extra. Corpus Iuris Canonici (1234).

Helmholz, Richard H., Kanonisches Recht und europäische Rechtskultur (Tübingen, 2013).

Kaser, Max, Das Römische Privatrecht (2 Ed., München, 1971), I.

Kaser, Max; HaCKL, Karl, Das römische Zivilprozessrecht (2a ed., München, 1996). 
KuPISCH, Berthold, In integrum restitutio und vindicatio utilis bei Eigentumsübertragungen im klassischen römischen Recht (Berlin, 1974).

Landau, Peter, "Aequitas" in the "Corpus Iuris Canonici", en Syracuse Journal of International Law and Commerce, 20 (1994).

Las Clementinae, Corpus Iuris Canonici (1314).

LeVene, Ricardo, En el tercer centenario de "Politica indiana" de Juan de Solórzano Pereira, 20 (Buenos Aires, Argentina, 1948).

Malagón Barceló, Javier; Ots Capdequí, José María, Solórzano y la política indiana (2a ed., Ciudad de México, 1983).

Novarius, Joannes Maria, De privilegiis miserabilium personarum tractatus (Lausonii et Colonia Allobrogum, 1739).

NovoA, Mauricio, Derecho romano y el indio americano en Solórzano, en BIRA., 26 (Lima, 1999), pp. 253-272.

NovoA, Mauricio, Novoa, Mauricio. La práctica judicialy su influencia en Solórzano: la audiencia de Lima y los privilegios de indios a inicios del siglo XVII, en BONNETT, Diana (coord.), Pensar la colonia desde la colonia (Bogotá, Ediciones Uniandes, 2006).

NovoA, Mauricio, The Protectors of Indians in the Royal Audience of Lima: History, Careers and Legal Culture, 1575-1775 (Leiden-Boston, 2016).

ODd, Sforza degli, De restitutione in integrum tractatus (ed. Colonia Agrippina, 1705).

Owensby, Brian P., Empire of Law and Indian Justice in Colonial Mexico (Stanford, 2008).

PEREYRA, Benedicto, Elucidarium sacrae theologiae moralis et juris utriusque: exponens universum idioma, id est proprietatem sermonis theologici, canonici, \& civilis (Venetiis, sumptibus Combi \& Lanouii, 1678).

Ruigómez Gómez, Carmen, Una politica indigenista de los Habsburgo: el protector de indios en el Perú (Madrid, 1988).

STAGL, Jakob, Das "testamentum militare" in seiner Eigenschaft als "ius singulare", en Revista de Estudios Histórico-Jurídicos, 36 (2014), pp. 129-157.

STAGL, Jakob, Favor dotis - Die Privilegierung der Mitgift im System des römischen Rechts (Böhlau, Viena, Austria, 2009).

SuÁrez, Francisco, Tractatus de legibus ac Deo legislatore: in decem libros distributus (Paris, 1613).

Van Hove, Alphonse, De legibus ecclesiasticis (Mechliniae, Dessain, 1930).

Wohlhaupter, Eugen, Aequitas canonica. Eine Studie aus dem Kanonischen Recht (Paderborn, Schöningh, 1931). 